\title{
Alterations in early auditory evoked potentials in multiple sclerosis patients
}

\section{Tania Mara Assis Lima1, Aline Nascimento Crato', Patrícia Cotta Mancini ${ }^{3}$, Lília Correa Simões ${ }^{4}$ Denise Utsch Gonçalves 5}

Keywords: multiple sclerosis, auditory evoked potentials, brainstem.

\section{Summary}

\begin{abstract}
A -lterations in early auditory evoked potentials (EAEP) in individuals with demyelinating disease are suggestive of lesions in the brainstem. Aim: this study aims to evaluate the prevalence of hearing disorders and altered EAEP in multiple sclerosis (MS) patients. Materials and method: sixteen female and nine male patients with a defined diagnosis of multiple sclerosis took part in this study. All individuals underwent hearing and EAEP tests. The wave forms were categorized according to Jerger (1986). Results: fifty EAEP tests were carried out; 70\% were classified as type I (normal response) according to Jerger's criteria. Altered EAEP results in at least one ear were classified into types II, III, IV or $\mathrm{V}$ according to Jerger. Females accounted for $31.25 \%$ of alterations, and males $44.44 \%$, adding up to $36 \%$ of all cases. Conclusions: these findings stress the importance of looking at EAEP in cases where there is suspicion of demyelinating disease and in patients with a defined diagnosis for MS.
\end{abstract}

\footnotetext{
${ }^{1} \mathrm{PhD}$ in Otorhinolaryngology, Adjunct Professor in the Department of Otorhinolaryngology at FM UFMG. ${ }^{2}$ Speech and Hearing Therapist.

${ }^{3}$ MSc in Linguistics, Associate Professor in the Department of Speech and Hearing Therapy at FM UFMG. ${ }^{4}$ Speech and Hearing Therapist in the Audiology Ward at Hospital das Clínicas da UFMG.

${ }^{5} \mathrm{PhD}$ in Tropical Medicine, Adjunct Professor in the Department of Otorhinolaryngology at FM UFMG UFMG Medical School, Hospital das Clínicas da UFMG.

Send correspondence to: Tânia Mara Assis Lima - Rua do Ouro 229/502 30220-000 Belo Horizonte MG.

This paper was submitted to the RBORL-SGP (Publishing Manager System) on 7 July 2007. Code 4645.

The article was accepted on 2 November 2007.
} 


\section{INTRODUCTION}

Brainstem auditory evoked potentials (BAEP) are short latency potentials generated in the auditory nerve and in the auditory pathways of the brainstem as the cochlea is activated in frequencies ranging between 2000 and $4000 \mathrm{~Hz}$ after the introduction of sound stimuli. They are characterized by a series of positive peak waves that come up within the first 10 milliseconds (ms) and that represent the summation of the neural activity of one or more sites. The more important waves are the rising ones, namely I, III, and $\mathrm{V}^{1}$.

BAEP results are altered in neurologic disorders introduced by tumors, diffuse lesions, demyelinating diseases, or functional disorders ${ }^{2}$.

Multiple sclerosis (MS) is the most common type of demyelinating disease and the main cause of neurologic damage in young adults. This is a slow, progressive disease that features periods of symptom exacerbation and remission ${ }^{3}$ and huge variation between individuals, depending on the site of the lesion ${ }^{4}$.

BAEP tests in individuals with demyelinating disease are important to assess central nervous system involvement ${ }^{5}$. The incidence of altered results in MS patients reported in the literature varies considerably. Wave I is almost always normal in patients without hearing loss. The anomalies found in patients with MS include: prolonged wave latency and intervals between peaks; reduced amplitude on wave $\mathrm{V}$; reduced wave $\mathrm{V} / \mathrm{I}$ amplitude ratio; absent wave $\mathrm{V}^{6}$.

The goal of this study is to assess the incidence of hearing disorders and altered BAEP test results in individuals with multiple sclerosis, looking at hearing thresholds and absolute latencies, intervals between peaks, wave characteristics, morphology and reproducibility.

\section{MATERIALS AND METHOD}

This study was approved by the UFMG-COEP Ethics Committee under permit 052/2004. Sixteen female and nine male patients from the Multiple Sclerosis Research Center (Centro de Investigação em Esclerose Múltipla - CIEM) were enrolled in the study. All had clinically defined diagnosis for multiple sclerosis according to the criteria set by Poser ${ }^{7}$. Clinical manifestations were categorized according to the principles proposed by Lubin and Reingold ${ }^{8}$. The female patient group's age ranged between 33 and 53 years (mean 42.6 years) while the male patient group was aged between 24 and 56 years (mean 38 years).

All patients were interviewed and underwent clinical ENT examination, tympanometry, tone audiometry, and BAEP tests.
The criteria defined by Russo ${ }^{9}$ were used to sort tympanometry results. Audiometry results were classified according to the principles defined by Davis and Silver$\operatorname{man}^{10}$

On the BAEP tests we used a sound stimulus of 1024 clicks introduced by a TDH-39 rarefied polarity supra-auricular transducer in $100 \mathrm{~ms}$ pulses, at $60 \mathrm{~dB}$ of sound pressure level above the psychoacoustic threshold of each subject. Stimuli were presented in one ear at a time, masked by white noise in the contralateral ear at 30dB SPL.

High pass filters at $3000 \mathrm{~Hz}$ and low pass filters at $100 \mathrm{~Hz}$ were used. Clicks were introduced at a rate of 13.1/ sec on the right ear and then on the left ear.

The criteria defined by Munhoz ${ }^{11}$ were used to define normal BAEP findings.

Waves were categorized as defined by Jerger ${ }^{12}$ :

Type I: normal response; all waves (I-V) had normal latencies and between peak intervals.

Type II: prolonged interval I-V.

Type III: degraded wave form; poor morphology; peaks hard to tell apart and/or reduced amplitude; and/ or altered amplitude ratios.

Type IV: absent last waves; absent last waves, first waves present with normal latency.

Type V: extremely altered response or only wave I normal.

\section{RESULTS}

Fifty-six percent of the 25 patients enrolled in the study had acute remissive MS, as shown in Table 1. Sixtyeight percent of the patients had tone hearing thresholds within normal range, and other cases of hearing loss did not interfere with BAEP acquisition (Tables 2 and 3).

From the 50 BAEP tests done, $70 \%$ were categorized as type I. Prolonged intervals between peaks I-V were found in $6.25 \%$ of the female subjects and $11.11 \%$ of the male patients, and they were categorized as type II. Wave form degradation and poor morphology was found in $5.55 \%$ of the male group, and they were categorized as type III. Type IV was not found. Type V, with more altered tracings, occurred in $18.75 \%$ of females and $22.22 \%$ of males (Table 4).

Subjects with types II, III, and IV were considered to have altered BAEP results in at least one ear. Thirtysix percent of the patients had altered BAEP results, with incidences of $31.25 \%$ among females and $44.44 \%$ among males (Table 5).

Individual values of absolute latency and between peak intervals in MS patients can be seen on Charts 1 and 2 . 
Table 1. MS Clinical forms according to the Lublin and Reingold Classification

\begin{tabular}{|c|c|c|c|c|c|c|}
\hline \multirow[b]{3}{*}{ Clinical form } & \multicolumn{6}{|c|}{ Gender } \\
\hline & \multicolumn{2}{|c|}{ Female } & \multicolumn{2}{|c|}{ Masculino } & \multicolumn{2}{|c|}{ Total } \\
\hline & & Male & $\mathrm{N}$ & $\%$ & $\mathrm{~N}$ & $\%$ \\
\hline Remission flare & & 62,50 & 4 & 44,44 & 14 & 56 \\
\hline Progressive flare & 1 & 6,25 & 2 & 22,22 & 3 & 12 \\
\hline Secondary progressive & 0 & 0 & 0 & 0 & 0 & 0 \\
\hline Primary progressive & 5 & 31,25 & 3 & 33,33 & 8 & 32 \\
\hline TOTAL & 16 & 100 & 9 & 100 & 25 & 100 \\
\hline
\end{tabular}

$\mathrm{N}=$ number

Table 2. Hearing loss classification as to intensity according to Davis and Silverman

\begin{tabular}{|c|c|c|c|c|c|c|c|c|}
\hline \multirow[b]{3}{*}{ Classification } & \multicolumn{4}{|c|}{ Females } & \multicolumn{4}{|c|}{ Males } \\
\hline & \multicolumn{2}{|c|}{$\mathrm{RE}$} & \multicolumn{2}{|c|}{ LE } & \multicolumn{2}{|c|}{ RE } & \multicolumn{2}{|c|}{ LE } \\
\hline & $\mathrm{N}$ & $\%$ & $\mathrm{~N}$ & $\%$ & $\mathrm{~N}$ & $\%$ & $N$ & $\%$ \\
\hline Normal & 12 & 75 & 11 & 68,75 & 6 & 66,66 & 6 & 66,66 \\
\hline Mild & 1 & 8,33 & 1 & 6,25 & 2 & 22,22 & 2 & 22,22 \\
\hline Moderate & 3 & 16,66 & 4 & 25 & 1 & 11,11 & 1 & 11,11 \\
\hline Severe & 0 & 0 & 0 & 0 & 0 & 0 & 0 & 0 \\
\hline Profound & 0 & 0 & 0 & 0 & 0 & 0 & 0 & 0 \\
\hline TOTAL & 16 & 100 & 16 & 100 & 9 & 100 & 9 & 100 \\
\hline
\end{tabular}

$\mathrm{N}=$ number RE: Right ear LE: Left ear

Table 3. Tonal audiometry results according to Davis e Silverman

\begin{tabular}{lccccccc}
\hline & \multicolumn{2}{c}{ Females } & \multicolumn{3}{c}{ Males } & \multicolumn{2}{c}{ Total } \\
\hline Audiometry & $\mathrm{N}$ & $\%$ & $\mathrm{~N}$ & $\%$ & $\mathrm{~N}$ & $\%$ \\
Normal & 11 & 68,75 & 6 & 66,66 & 33,33 & 68 & 8 \\
Altered & 5 & 31,25 & 3 & 100 & 25 & 32 \\
\hline TOTAL & 16 & 100 & 9 & & & 100 \\
\hline
\end{tabular}

$\mathrm{N}=$ number

Table 4. Classification of wave types according to Jerger

\begin{tabular}{|c|c|c|c|c|c|c|}
\hline & \multicolumn{2}{|c|}{ Females } & \multicolumn{2}{|c|}{ Males } & \multicolumn{2}{|c|}{ Total } \\
\hline & $\mathrm{N}$ & $\%$ & $\mathrm{~N}$ & $\%$ & $\mathrm{~N}$ & $\%$ \\
\hline Type I & 24 & 75,00 & 11 & 61,11 & 35 & 70 \\
\hline Type II & 2 & 6,25 & 2 & 11,11 & 4 & 8 \\
\hline Type III & 0 & 0 & 1 & 5,55 & 1 & 2 \\
\hline Type IV & 0 & 0 & 0 & 0 & 0 & 0 \\
\hline Type V & 6 & 18,75 & 4 & 22,22 & 10 & 20 \\
\hline TOTAL & 32 & 100 & 18 & 100 & 50 & 100 \\
\hline
\end{tabular}

$\mathrm{N}=$ number 
Table 5. Classification of BAEP in both genders

\begin{tabular}{|c|c|c|c|c|c|c|}
\hline & \multicolumn{2}{|c|}{ Females } & \multicolumn{2}{|c|}{ Males } & \multicolumn{2}{|c|}{ Total } \\
\hline & $\mathrm{N}$ & $\%$ & $\mathrm{~N}$ & $\%$ & $\mathrm{~N}$ & $\%$ \\
\hline Normal & 11 & 68,75 & 5 & 55,55 & 16 & 64 \\
\hline Altered & 5 & 31,25 & 4 & 44,44 & 9 & 36 \\
\hline TOTAL & 16 & 100 & 9 & 100 & 25 & 100 \\
\hline
\end{tabular}

$\mathrm{N}=$ number

Chart 1. Individual values of absolute latencies and interpeak intervals of female individuals

\begin{tabular}{|c|c|c|c|c|c|c|c|c|c|c|c|}
\hline \multicolumn{6}{|c|}{ Waves } & \multicolumn{6}{|c|}{ Interpeak intervals } \\
\hline \multicolumn{2}{|c|}{ I } & \multicolumn{2}{|c|}{ III } & \multicolumn{2}{|c|}{ V } & \multicolumn{2}{|c|}{$|-| I \mid$} & \multicolumn{2}{|c|}{ III-V } & \multicolumn{2}{|c|}{$\mathrm{I}-\mathrm{V}$} \\
\hline RE & LE & RE & LE & RE & LE & RE & LE & RE & LE & RE & LE \\
\hline 1,52 & 1,56 & 3,44 & 3,40 & 5,52 & 5,72 & 1,92 & 1,84 & 2,08 & 2,32 & 4,00 & 4,16 \\
\hline 1,48 & 1,76 & 3,28 & 3,52 & 5,20 & 5,72 & 1,80 & 1,76 & 1,92 & 2,20 & 3,72 & 3,96 \\
\hline 1,60 & 1,60 & 3,48 & 3,52 & 5,48 & 5,60 & 1,88 & 1,92 & 2,00 & 2,08 & 3,88 & 4,00 \\
\hline 1,68 & 1,72 & 3,88 & 3,96 & 6,00 & 5,92 & 2,20 & 2,24 & 2,12 & 1,96 & 4,32 & 4,20 \\
\hline 1,56 & 1,56 & 3,88 & 3,80 & 5,28 & 4,88 & 2,32 & 2,24 & 1,40 & 1,08 & 3,72 & 3,32 \\
\hline 1,44 & 1,76 & 3,44 & 3,44 & 5,16 & 5,72 & 2,00 & 1,68 & 1,72 & 2,28 & 3,72 & 3,96 \\
\hline 1,56 & 1,72 & 3,68 & 3,52 & 5,56 & 5,72 & 2,12 & 1,80 & 1,88 & 2,20 & 4,00 & 4,00 \\
\hline 1,64 & 1,60 & 3,88 & 3,80 & 5,84 & 5,92 & 2,24 & 2,20 & 1,96 & 2,12 & 4,20 & 4,32 \\
\hline 1,68 & 1,56 & 3,84 & 3,80 & 5,36 & 5,36 & 2,16 & 2,24 & 1,52 & 1,56 & 3,68 & 3,80 \\
\hline- & - & - & - & - & - & - & - & - & - & - & - \\
\hline- & - & - & - & - & - & - & - & - & - & - & - \\
\hline 1,64 & 1,80 & 3,48 & 3,60 & 6,24 & 5,88 & 1,84 & 1,80 & 2,76 & 2,28 & 4,60 & 4,08 \\
\hline 1,60 & 1,40 & 4,16 & 3,60 & 6,24 & 5,28 & 2,56 & 2,20 & 2,08 & 1,68 & 4,64 & 3,88 \\
\hline 1,12 & 1,16 & 2,80 & 2,84 & 4,64 & 4,76 & 1,68 & 1,68 & 1,84 & 1,92 & 3,52 & 3,60 \\
\hline 1,36 & 1,36 & 3,56 & 3,48 & 5,60 & 5,44 & 2,20 & 2,12 & 2,04 & 1,96 & 4,24 & 4,08 \\
\hline
\end{tabular}

RE: Right Ear LE: Left Ear

Chart 2. Individual values of absolute latencies and interpeak intervals of males

\begin{tabular}{|c|c|c|c|c|c|c|c|c|c|c|c|}
\hline \multicolumn{6}{|c|}{ Waves } & \multicolumn{6}{|c|}{ Interpeak Intervals } \\
\hline \multicolumn{2}{|c|}{ I } & \multicolumn{2}{|c|}{ III } & \multicolumn{2}{|c|}{ V } & \multicolumn{2}{|c|}{ |-III } & \multicolumn{2}{|c|}{ III-V } & \multicolumn{2}{|c|}{$\mathrm{I}-\mathrm{V}$} \\
\hline $\mathrm{RE}$ & LE & $\mathrm{RE}$ & LE & $\mathrm{RE}$ & LE & $\mathrm{RE}$ & LE & $\mathrm{RE}$ & LE & $\mathrm{RE}$ & LE \\
\hline 1,52 & 1,56 & 3,76 & 3,64 & 5,48 & 5,48 & 2,24 & 2,08 & 1,72 & 1,84 & 3,96 & 3,92 \\
\hline 1,60 & 1,44 & 3,64 & 3,60 & 5,56 & 5,60 & 2,04 & 2,16 & 1,92 & 2,00 & 3,96 & 4,16 \\
\hline- & - & - & - & - & - & - & - & - & - & - & - \\
\hline 1,12 & 1,12 & 3,28 & 3,20 & 5,32 & 5,32 & 2,16 & 2,08 & 2,04 & 2,12 & 4,20 & 4,20 \\
\hline 1,48 & 1,60 & 3,80 & 4,52 & 5,96 & 6,80 & 2,32 & 2,92 & 2,16 & 2,28 & 4,48 & 5,20 \\
\hline 1,48 & 1,64 & 3,84 & 3,72 & 5,80 & 5,80 & 2,36 & 2,08 & 1,96 & 2,08 & 4,32 & 4,16 \\
\hline 1,40 & - & - & - & - & - & - & - & - & - & - & - \\
\hline 1,40 & 1,24 & 3,76 & 3,84 & 5,12 & 5,92 & 2,36 & 2,60 & 1,36 & 2,08 & 3,72 & 4,68 \\
\hline 1,48 & 1,48 & 3,64 & 3,84 & 5,80 & 5,92 & 2,16 & 2,36 & 2,16 & 2,08 & 4,32 & 4,44 \\
\hline
\end{tabular}

RE: Right Ear LE: Left Ear 


\section{DISCUSSION}

Hearing loss in MS is sensorineural and bilateral in $85 \%$ of the cases ${ }^{3}$. In our study, tone audiometry results were altered in $32 \%$ (8) of the patients, with $87.5 \%$ having bilateral sensorineural hearing loss and $12.5 \%$ being affected by moderate left conductive hearing loss due to ear drum perforation. Jerger ${ }^{12}$ reported altered audiometry results in 39\% of multiple sclerosis patients, all of whom affected by sensorineural hearing loss.

MS neurologic symptoms are many, and may vary from case to case and throughout the progress of the disease. In Brazil, Lana-Peixoto and Lana-Peixoto13 found brainstem alterations in $34 \%$ of the individuals with manifestations compatible with early MS and 45\% with progressed disease. Papais-Alvarenga et al. ${ }^{14}$ found brainstem alterations in $28.4 \%$ of early MS patients and in $28.5 \%$ of patients with progressed MS. Tilbery et al. ${ }^{15}$ found signs and symptoms of brainstem alteration in 32\% of patients with early MS and in 52\% of patients with progressed disease.

Our study showed altered BAEP in 9 patients (36\%) in one or both ears, $31.25 \%$ of whom were females and $44.44 \%$ males. In $66.7 \%$ of these patients, altered results were found in both ears. Jerger ${ }^{12}$ found $52 \%$ of BAEP alteration in one or both ears, $68.75 \%$ of whom had bilateral hearing loss. Santos et al. ${ }^{16}$ found altered unilateral and bilateral results in $58.62 \%$ of the patients, $60 \%$ in females and $56 \%$ in males.

The most frequently found alteration in our study was type $\mathrm{V}^{12}$, as it occurred in $18.75 \%$ of females and $22.22 \%$ of males. Jerger12 reported type II alteration in $6.5 \%$, type III in $8 \%$, type IV in $16.1 \%$, and type V in $13 \%$ of patients. Santos ${ }^{16}$ reported type II in $32.8 \%$, type IV in $5 \%$, and type $\mathrm{V}$ in $7 \%$ of patients.

\section{CONCLUSION}

Thirty-six percent of the 25 patients with clinically diagnosed MS had brainstem alterations as found in BAEP tests, thus stressing the importance of this test in examining patients clinically suspected for demyelinating disease.

\section{REFERENCES}

1. Hall JW, Mueller G. Auditory brainstem response. In: Audiologists' desk reference: diagnostic audiology principles and procedures. San Diego: Singular Publishing Group.; 1997. p. 319-87.

2. Hood L. Clinical applications of the auditory brain response. San Diego: Singular Publishing Group.; 1998. p. 67-91.

3. Hall JW. Neurodiagnosis: central nervous system. In: Hall J W. Handbook of auditory evoked responses. Massachusetts: Allyn and Bacon; 1992. p. 419-72.

4. Smith CR, Schapiro R. Neurologia. In: Kalb RC. Esclerose Múltipla: perguntas e respostas. São Paulo: Abem; 2000. p. 27-59.

5. Chiappa KH. Evoked potentials in clinical medicine, 3 th ed. Philadelphia: Lippicott-Raven.; 1997. p. 1-30.

6. Nuwer MR. Evoked potencial in multiple sclerosis. In: Raine CS, McFarland HF, Tourtellotte WW. Multiple Sclerosis: clinical and pathogenetic basis. London: Chapman e Hall.; 1997. p. 43-55.

7. Poser CM, Paty DW, Scheinberg L, McDonald I, Davis FA, Ebers GC, et al. New diagnostic criteria for multiple sclerosis: guidelines for reseach protocols. Ann Neurol. 1983;13:227-31.

8. Lublin FD, Reingolg SC. Defining the clinical course of multiple sclerosis results of international survey. Neurology. 1996;46:907-11.

9. Russo ICP. Achados imitanciométricos em pré-escolares de níveis sócio econômico baixo, médio e alto: estudo comparativo. Acta AWHO. 1988;4:229-35.

10. Davis H, Silverman SR. Hearing and Deafness. New York: Copyright, 1970.

11. Munhozms L, Frazza MM, Silva MLG, Ganança MM, Caovilla HH. Avaliação audiológica avançada: audiometria de altas freqüências, otoemissões acústicas e testes de processamento auditivo central. Atualidades em Geriatria.; 1998. p. 13-18.

12. Jerger JF, Oliver TA, Chmiel RA, Rivera VM. Patterns of auditory abnormality in multiple sclerosis. Audiology. 1986;25:193-209.

13. Lana-Peixoto MA, Lana-Peixoto MI. Is multiple sclerosis in Brazil and Asia alike? Arq Neuropsquiatr. 1992;4:419-25.

14. Papais-Alvarenga RM, Santos CMM, Abreu JS, Siqueira H, Camargo SMGG, Almeida AMV, et al. Esclerose múltipla: perfil clínico e evolutivo no município do Rio de Janeiro. Rev Bras Neurol. 1995;2:75-87.

15. Tilbery CP, Felipe E, Baldauf CM, Peres MFP. Esclerose múltipla: análise clínica e evolutiva de 214 casos. Arq Neuropsquiatr. 1995;53:203-7.

16. Santos MAR, Lana-Peixoto MA, Munhoz MSL, Almeida AVA. Avaliação dos potenciais evocados auditivos do tronco encefálico na esclerose múltipla. Arq Neuropsiquiatr. 2003;61:392-7. 